\title{
PROMOVER A SAÚDE NO NOVO PARADIGMA
}

\author{
Ana Paula Macedo \\ Universidade do Minho - UMinho - Braga - Portugal
}

Judite Maria Cruz

Universidade do Minho - UMinho - Braga - Portugal

\section{Jaime Moreira Ribeiro}

Politécnico de Leiria - Escola Superior de Saúde \& CIDTFF - Universidade de Aveiro - Aveiro - Portugal

O movimento internacional em torno da promoção da saúde teve início na década de 80 do século XX. A I Conferência Internacional sobre Promoção da Saúde, em novembro de 1986, em Ottawa, Canadá, sinaliza o marco histórico para a mudança de paradigma. As discussões baseadas na Declaração de Alma-Ata para os Cuidados Primários em Saúde, no documento da OMS sobre Saúde Para Todos, assim como no debate ocorrido na Assembleia Mundial da Saúde originaram a 'Carta de Ottawa'(1). De acordo com o documento: "Promoção da saúde é o nome dado ao processo de capacitação da comunidade para atuar na melhoria de sua qualidade de vida e saúde, incluindo uma maior participação no controle deste processo"(1).

Promover a saúde é hoje uma obrigação nos diversos sistemas de saúde, articulada a ações que visam dar resposta à diversidade de necessidades sociais não dissociadas das potencialidades humanas. No novo paradigma de intervenção do setor da saúde a abordagem extravasa as considerações nacionais, apelando à participação de atores e de parcerias e à articulação entre a investigação e a prática clínica. Neste pacto, todos terão um papel a desempenhar na disseminação de práticas de referência - os cidadãos, os profissionais de saúde, os educadores, os trabalhadores dos vários setores, autarquias e o Governo(2). As mudanças que se avizinham nos próximos anos implicarão desafios para todos os setores da sociedade (desde a educação, ao meio ambiente, à economia, à qualidade dos serviços e às competências dos profissionais), em que as políticas assumirão um papel importante pela sua exigência na promoção de saúde ${ }^{(3)}$.

A investigação que tem sido feita, neste âmbito, destaca que as necessidades regionais específicas, identificadas durante o processo de construção da política, reforçam a riqueza de desenvolver, de forma inovadora, democrática e participativa, ações que possam dar sentido à promoção da saúde. É o exemplo do estudo que anuncia a sustentabilidade das políticas públicas de promoção de saúde, destacando a formação de redes colaborativas, além de consistência política e legislativa que permita a continuidade das intervenções ${ }^{(4)}$. Já outros estudos, oriundos de processos de revisão na área política, enunciam a sua importância pelo seu contributo na produção e difusão do conhecimento na área, subsidiando diretrizes e mecanismos de pesquisa, formação e educação permanente sobre a temática.

É o caso do estudo que destaca a necessidade da constituição de novos arranjos de advocacy e boa governança mediante a criação de espaços de articulação intergovernamental e intersectorial, caminho que tende para a ascensão e participação regional no processo de formulação de uma política. Encontros de trabalho coletivo parecem dar conta de uma aprendizagem inter-regional, intersectorial e intergeracional, pela existência de validação dos pares e parceiros, além das contribuições deste processo para o fortalecimento da agenda estratégica da Saúde Coletiva( ${ }^{(5)}$.

Neste processo de transição as iniciativas dos cidadãos e da sociedade em geral serão fundamentais na redução das doenças crónicas, no incremento da qualidade e no acesso a evidências científicas, sem, no entanto, perder o reforço do papel do Estado na garantia das condições de vida à população, "para não se correr o risco de se afirmar uma política que, principalmente, culpabiliza e responsabiliza o indivíduo pela sua não saúde”(6).

Esta edição da RBPS apresenta resultados de estudos de interesse diversificado no campo da promoção da saúde, geradores de reflexões nos leitores interessados pelos temas. Integra onze artigos em português, 
selecionados entre aqueles que foram apresentados no $6^{\circ}$ Congresso Ibero-Americano em Investigação Qualitativa (www.ciaiq.org), que teve lugar em Salamanca em Julho de 2017. Para a sua seleção foi considerada a avaliação dos artigos pela comissão científica do CIAIQ. Foram ainda sujeitos a ampliação e a verificação pelos editores convidados. A seleção considerou ainda os objetivos editoriais da RBPS. Pretende-se com esta edição contribuir para o desenvolvimento científico, teórico e metodológico em Saúde como ciência e profissão.

Mais uma vez exprime, inequivocamente, que a promoção de saúde é um campo vasto de estudo, cuja pluralidade explica a diversidade dos problemas, questões de investigação e opções metodológicas. Destaca-se a natureza qualitativa comum aos artigos que constam desta edição, uma abordagem cada vez mais presente na investigação na área da saúde, uma vez que contactar com as diferentes perspetivas e significações dos fenómenos do processo saúde-doença contribui efetivamente para a promoção da saúde, promovendo uma maior adesão em ações de saúde implementadas individual e coletivamente, através de respostas ajustadas a recetores e prestadores de serviços de saúde ${ }^{(7)}$.

A discussão dos estudos que se seguem contribui para fortalecer a comunidade científica, que se identifica tanto pela elucidação das práticas, como pelo fundamento teórico, abrindo o leque de abordagens no terreno da ação.

\section{REFERÊNCIAS}

1. Malta DC, Morais Neto OL, Silva MM, Rocha D, Castro AM, Reis AA, dos et al. National Health Promotion Policy (PNPS): chapters of a journey still under construction. Cien. Saúde Colet. [Internet]. 2016 June; [cited 2018 Jan 01]; 21(6):1683-1694. Available from: http://www.scielo.br/scielo.php?script=sci_arttext\&pid=S141381232016000601683\&lng=en.http://dx.doi.org/10.1590/1413-81232015216.07572016.

2. Fundação Calouste Gulbenkian (FCG). Um Futuro para a Saúde: todos temos um papel a desempenhar. Portugal: Fundação Calouste Gulbenkian; 2014 [accessed 2 January 2018]. https://s3-eu-central-1.amazonaws.com/content. gulbenkian.pt/wp-content/uploads/2016/03/30003652/PGIS_BrochuraRelatorioCompletoHealthPortugues.pdf

3. Campos DS, Turci MA, Melo EM, Guerra VA, Nascimento CGM, Moreira CA, Paschoal EM, Beltrão NRM1, Silva KR. Participatory construction of the State Health Promotion Policy: a case from Minas Gerais, Brazil. Cien Saude Colet. 2017 Dec; 22(12):3955-3964. doi: 10.1590/1413-812320172212.25062017

4. Moyses SJ, Moyses ST, krempel MC. Assessing the building process of health promotion public policies: the experience of Curitiba. Ciênc. saúde coletiva [online]. 2004, 9 (3): 627-641.

5. Rocha DG, Alexandre VP, Marcelo VC, Rezende R, Nogueira JD, Franco de Sá R. The review process of the National Health Promotion Policy: simultaneous multiple movements. Cien Saude Colet. 2014 Nov; 19(11): 4313-4322.

6. Silva PF, Baptista TW. National Health Promotion Policy: text and context of a policy Saúde Debate Rio De Janeiro. 2015 Dec; 39 (número especial): 91-104, pp.103.

7. Ribeiro, J, Neri de Souza, D, Costa, AP. Investigação qualitativa na área da saúde: por quê?. Ciência \& Saúde Coletiva [online]. 2016; 21(8): 2324.

\section{Endereço para correspondência:}

Jaime Moreira Ribeiro

Politécnico de Leiria - Escola Superior de Saúde \& CIDTFF

Escola Superior de Saúde - Campus 2

Morro do Lena - Alto do Vieiro

Apartado 4163

2411-901 - Leiria - Portugal

E-mail: jaime.ribeiro@ipleiria.pt

\section{Endereço do primeiro autor:}

Ana Paula Macedo

Universidade do Minho

Largo do Prado

4704-553 - Braga - Portugal

E-mail: amacedo@ese.uminho.pt 